\title{
Effects of Rapid Maxillary Expansion on Nasal Cavity Dimensions and Resistance
}

\author{
María E. Tapia ${ }^{1}$, Ursula Brethauer ${ }^{2, *}$, Patricio Ulloa ${ }^{3}$, Andrea Carcamo ${ }^{4}$, and \\ Felipe Culaciati ${ }^{5}$
}

${ }^{1}$ Facultad de Odontología, Universidad de Concepción, Roosevelt 1550, Concepción, Chile; ${ }^{2}$ Private Practice of Orthodontics, Cochrane 1120, Concepción, Chile; ${ }^{3}$ Facultad de Medicina, Universidad de Concepción, Chacabuco 1343, Concepción, Chile; ${ }^{4}$ Facultad de Ciencias de la Ingeniería, Universidad Austral, General Lagos 2086, edificio 6000, campus Miraflores, Valdivia, Chile; and ${ }^{5}$ Private Practice, Clínica Las Lilas, Eliodoro Yañez 2087, Providencia, Santiago, Chile.

\begin{abstract}
Rapid maxillary expansion is a common treatment for posterior cross-bites that has also been shown to improve nasal breathing. Thirteen oral breather patients with posterior cross-bite were studied. Treatment consisted of rapid maxillary expansion with a fully bonded appliance including a bite-block and a hyrax expansion screw. Before and after treatment, CT scans and active anterior rhinomanometry were performed on each patient. Data were analyzed with the non-parametric Wilcoxon statistical test and correlation between palatal expansion and increase of airflow in each patient was assessed. Transversal dimensions were significantly increased $(\mathrm{P}<0.05)$ in all areas after treatment, considering the right and left side separately. Rhinomanometry parameters before and after treatment also showed statistical differences $(P<0.001)$. Positive correlation was observed between palatal expansion and increased airflow. All patients improved his/her oral breathing habit clinically.
\end{abstract}

Keywords: Oral breathing, Rapid maxillary expansion, Rhinomanometry, Airway resistance, Face development.

\section{INTRODUCTION}

Normal breathing involves adequate utilization of the nasopharyngeal tract. The air must pass freely and fluently through the nostrils with minimal resistance [1]. Unusual enlargement of anatomical structures in this area, such as adenoids, hypertrophy of nasal turbinates or tonsils, nasal injury, nasal septum deviation, neoplasms, congenital nasal deformities, foreign bodies, polyps, or allergic rhinitis, can obstruct the airflow within the nasorespiratory channel [1-6]. This obstruction can impair nasal breathing, resulting in an oral mode of respiration [1]. Some authors contend that oral breathing can be a habit [7].

Oral breathing can result in developmental longterm alterations, causing postural adaptations of the vertebral column, thoracic cavity, and craniofacial structures [8]. Craniofacial anomalies typically include anterior head posture, reduced development of the middle third of the face, increased anterior face height, steep mandibular

Address correspondence to Ursula Brethauer, Cochrane 1120, Concepción, Chile; Tel: 56-9-97469615; Fax: 56-41-2216791;

E-mail: ubrethau@gmail.com plane angle, narrow external nares, incompetent lip posture, protrusion of upper incisors, "V" shaped maxillary arch, increased palatal depth, and a tendency towards anterior open bite [9-16]. Because the mandible has a lowered position, the tongue often adopts a low position, resulting in an underdeveloped upper jaw, bilateral compression, and posterior unilateral or bilateral cross-bite [13].

Rapid maxillary expansion (RME) has been an efficient treatment for posterior cross-bites since its introduction by Angell in 1860 [17]. It corrects the maxillary arch configuration and improves nasal breathing as a consequence of the separation of the palatal suture that results in widening of the nasal cavity and increased air permeability [18].

The nasal valve area is the narrowest part of the nasal cavity and it is the most resistant site to airflow $[19,20]$. It is located between the superior and inferior lateral cartilages and the pyriform notch, just beneath the anterior edge of the inferior turbinate. RME has its greatest effect on the anterior aspect of the palate, thus increasing the nasal valve area, resulting in an increase in nasal permeability $[21,22]$. The increase in nasal width has 
been traditionally measured by posteroanterior radiographs $[23,24]$. This exam has limitations due to superimposition of anatomical structures. Computerized tomography (CT) produces serial slices in the nasal cavity from the pyriform notch to the choanae and can be used to quantify changes obtained with treatment. Few studies have used CT scans to measure these changes $[25,26]$.

Respiratory function can be characterized by measuring the resistance of the airflow at the nasal cavity by rhinomanometry. This exam quantifies air resistance $[27,28]$. Rhinomanometry can be passive or active. During active rhinomanometry, the patient breaths continuously through the nose and measurements are made at the anterior or posterior area of the nasal cavity. Posterior rhinomanometry can be very unpleasant for the patient, especially children, because the instrument must be placed through the mouth into the posterior area of the nasal cavity. Resistance in each nasal cavity must be measured individually [29]. Anterior active rhinomanometry measures the resistance of the airflow at the nostrils and can be done separately on each side, detecting which side is more obstructed [30,31]. Anterior active rhinomanometry is simple and easy to perform, and therefore commonly used for the study of the nasal cycle and comparison of pre- and posttreatment results [32].

Little research has combined CT scan imaging and rhinomanometry to evaluate the anatomical and functional changes of the nasal cavities after RME [33]. Our study aimed to evaluate the nasal cavity anatomical structures by CT scan and the respiratory function by active anterior rhinomanometry in patients with oral breathing and posterior cross-bite before and after RME treatment.

\section{METHODS}

Thirteen patients (4 male, 9 female, age range 712-years-old, mean 9-years-old) were included in this study. All patients were mouth breathers and had bilateral cross-bite. None of these patients had previously undergone otorhinolaryngologic or orthodontic treatment. Each patient was evaluated clinically by an orthodontist and an otorhinolaryngologist. Panoramic radiographs, lateral and posteroanterior cephalograms, occlusal maxillary radiographs, dental casts, and clinical photographs were obtained to determine if the patient needed treatment. Study subjects could not have any acute respiratory pathology and could not use any anti-allergic medicine for 24 hours before each exam.

This study was approved by the bioethical board of the School of Dentistry, University of Concepción and informed consent was obtained from all patients' parents.

Clinical treatment consisted of RME with a fully bonded appliance, including a bite-block and an hyrax expansion screw (Figure 1). Each patient was instructed to turn the screw $1 / 4$ of a turn (0.25mm expansion) twice a day until the cross-

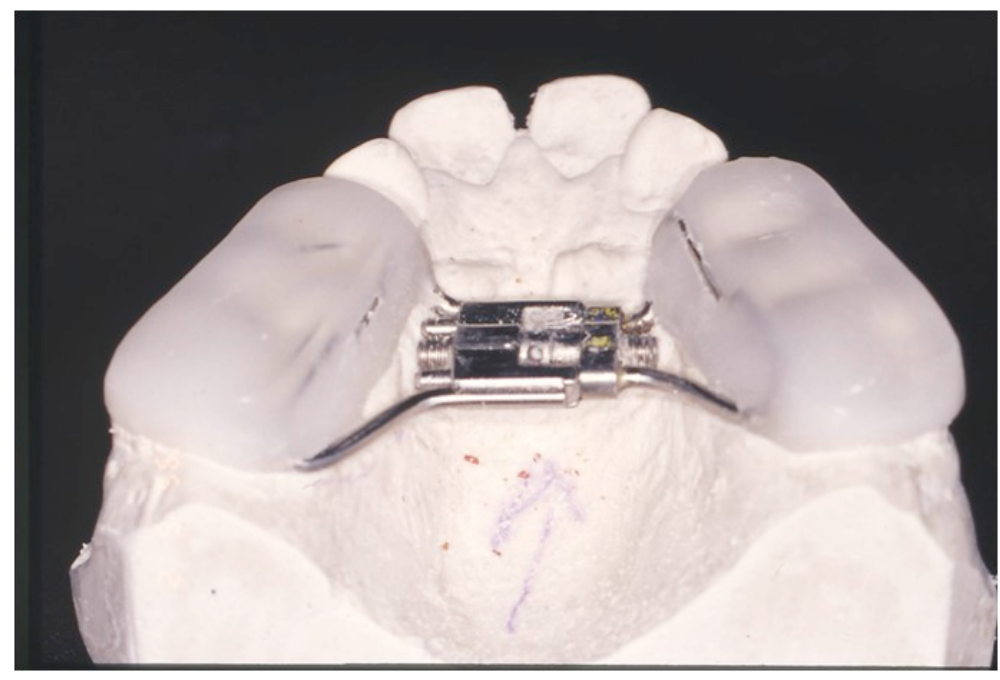

Figure 1. Full bonded appliance used for maxillary rapid expansion that included a bite-block and hyrax screw. 
bite was corrected. The appliance was left in place as a retention device for four months after treatment. The hyrax screw was inactivated by adding acrylic to the mechanism.

Before- and after-treatment CT scans and active anterior rhinomanometry were performed on each patient.

Three coronal slices were obtained from each patient with an helicoidal CT scanner (Somatom Plus 4, Siemens, Berlin, Germany). The anterior coronal slice was taken at the nasolacrimal duct, located at the same level as the pyriform notch. The middle coronal slice was taken at the beginning of the maxillary sinus ostium $\mathrm{m}_{2}$ and the posterior coronal slice was taken at the posterior border of the choanae (Figure 2). At each coronal slice, the right and left nasal cavity dimensions were measured at the widest portion of each side.

Active anterior rhinomanometry was used to quantitatively assess the air pressure through the nasal cavities. Patients were seated with a natural head position and measurements were obtained for 20 seconds during inhalation and exhalation, before and after administration of a decongestant (oximetazoline clorhidrate $0.05 \%$ ), in each side separately. Individual orthodontic treatment was performed for each patient after RME to fully correct their malocclusion.

Non-parametric Wilcoxon test was used to determine statistical differences. Differences were considered statistically significant when $P<0.05$. Correlation (Spearman) between degree of palatal expansion and increase in rhinomanometry flow was assessed in each patient.

\section{RESULTS}

Transversal dimensions were significantly increased $(P<0.05)$ after treatment in both sides (Table 1). Rhinomanometric parameters also increased (Table 2). When comparing the average amount of expansion with the increase of airflow in each patient, there was a positive correlation (Spearman, $\mathrm{R}=0.27$ ), but this correlation was not statistically significant (Spearman, $p=0.36$ ) (Figure 3).

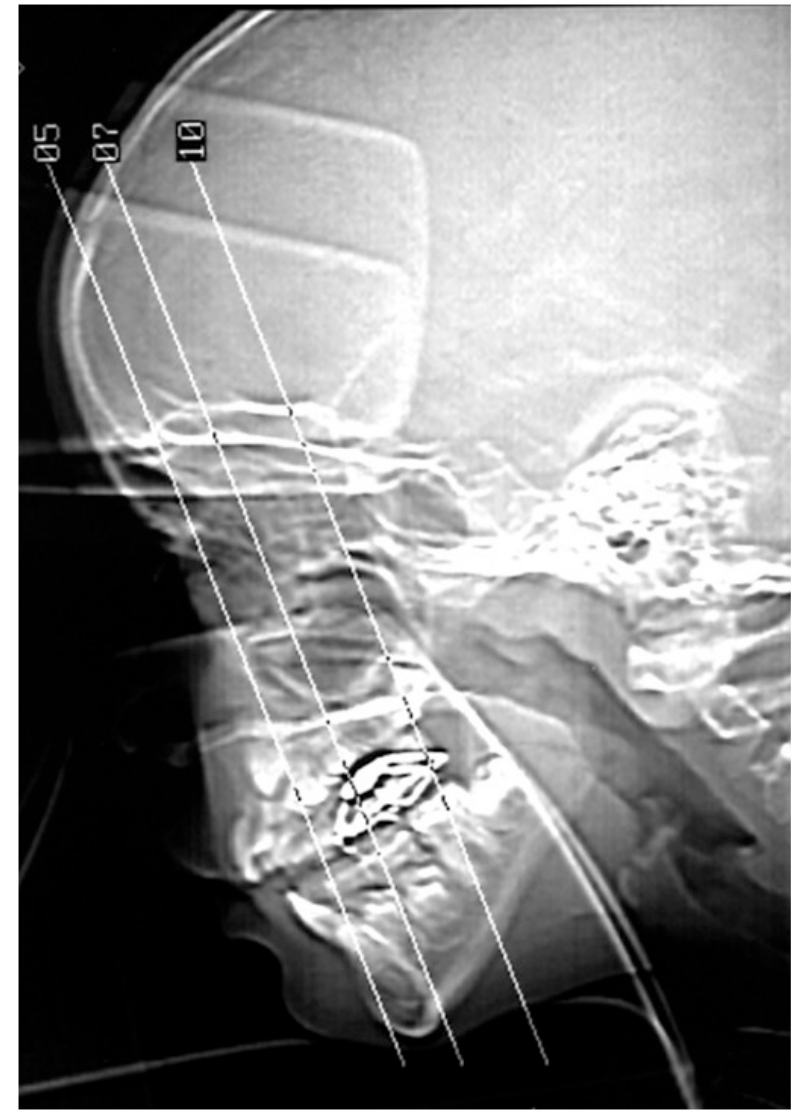

Figure 2. Three coronal slices were taken at the anterior, middle and posterior aspect of the nasal cavity.

Table 1. Mean Values and SD of CT Measurements before and after Rapid Maxillary Expansion

\begin{tabular}{|lcccccc|}
\hline & Before & SD & After & SD & Difference & P value $^{*}$ \\
\hline ACS right & 10.3 & 1.2 & 11.9 & 1.4 & 1.6 & $<0.05$ \\
ACS left & 10.4 & 1.3 & 12.2 & 1.6 & 1.8 & $<0.05$ \\
MCS right & 12.3 & 1.1 & 13.7 & 1.2 & 1.4 & $<0.05$ \\
MCS left & 12.6 & 1.3 & 13.8 & 1.2 & 1.2 & $<0.05$ \\
PCS right & 12.3 & 1.1 & 13.1 & 1.2 & 0.8 & $<0.05$ \\
PCS left & 12.7 & 1.1 & 13.6 & 1.3 & 0.9 & $<0.05$ \\
\hline
\end{tabular}

ACS: anterior coronal slice; MCS: middle coronal slice; PCS: posterior coronal slice. *Wilcoxon test. 
Table 2. Mean Measurements of Rhinomanometry Pre-and Post-Treatment

\begin{tabular}{|lllcccc|}
\hline & & & Pre-Treatment & Post-Treatment & Difference & P value $^{*}$ \\
\hline \multirow{3}{*}{ Inhalation } & \multirow{6}{*}{ With oximetazoline } & Right & 85.9 & 36.0 & 49.9 & $<0.001$ \\
& & Left & 58.3 & 25.2 & 33.1 & $<0.001$ \\
& \multirow{2}{*}{ Without oximetazoline } & Right & 127.9 & 63.7 & 64.2 & $<0.001$ \\
& & Left & 111.2 & 31.6 & 79.6 & $<0.001$ \\
& \multirow{3}{*}{ With oximetazoline } & Right & 132.6 & 31.0 & 101.6 & $<0.001$ \\
& & Left & 76.0 & 16.7 & 59.3 & $<0.001$ \\
& \multirow{2}{*}{ Without oximetazoline } & Right & 92.7 & 28.1 & 64.6 & $<0.001$ \\
& & Left & 119.5 & 27.6 & 91.9 & $<0.001$ \\
\hline
\end{tabular}

*Wilcoxon test.

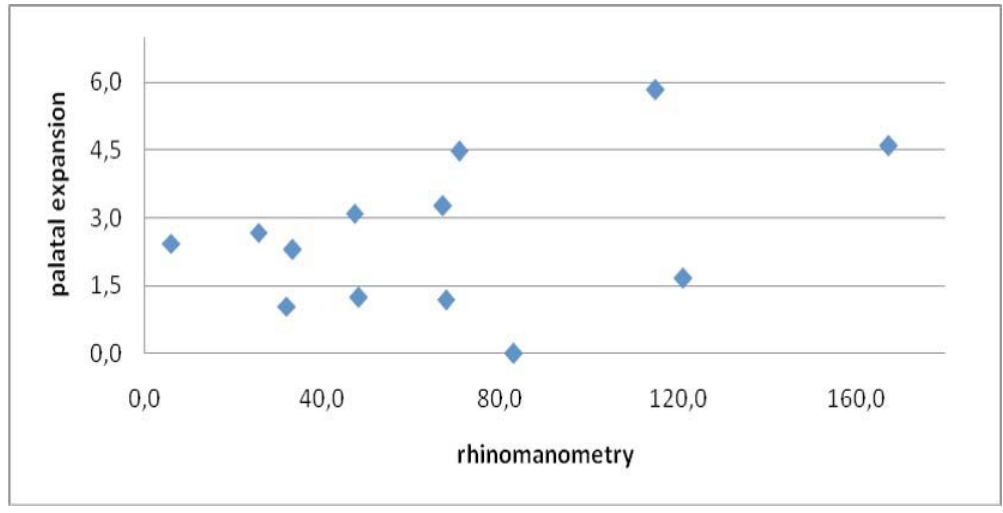

Figure 3. Correlation between amount of palatal expansion and increase in rhinomanometry flow in each patient (Spearman).

A clinical case is presented in Figures 4-8.

\section{DISCUSSION}

The present study showed that RME helps increase nasal breathing by widening the nasal bony structure and allowing more air to enter the nasal cavity as previously reported $[25,26]$. The most important differences before and after treatment were at the anterior portion of the nasal cavity, where the nasal valve is located and the greatest resistance to airflow was observed. This explains the significant clinical improvement that patients experienced. The posterior portion of the palate is more difficult to expand because of a locking effect of the pyramidal processes of the palatal bones into the pterigoid plates of the sphenoid [34]. Several studies determined a functional improvement in respiration after RME [3537]. The introduction of a decongestant like oximetazoline, however, is a significant aid to deter- mining the cause of the increased nasal resistance. If the decongestant reduced nasal resistance, the obstruction may have been influenced by soft-tissue problems, especially at the anterior aspect of the nasal airway [21].

Each patient studied had an increase in the CT scan measurements and a functional improvement measured by rhinomanometry. However, patients with the smallest differences in the rhinomanometric results were patients that presented turbinate hypertrophy or allergies.

Cone-beam computed tomography is generally preferred for research due to lower radiation doses [38], however, it was not available for the present study. Although CT scan imaging is still more expensive than conventional radiography, it is, in many aspects, a superior radiographic technique $[39,40]$. When acquired for orthodontic diagnosis, additional conventional radiographs can 


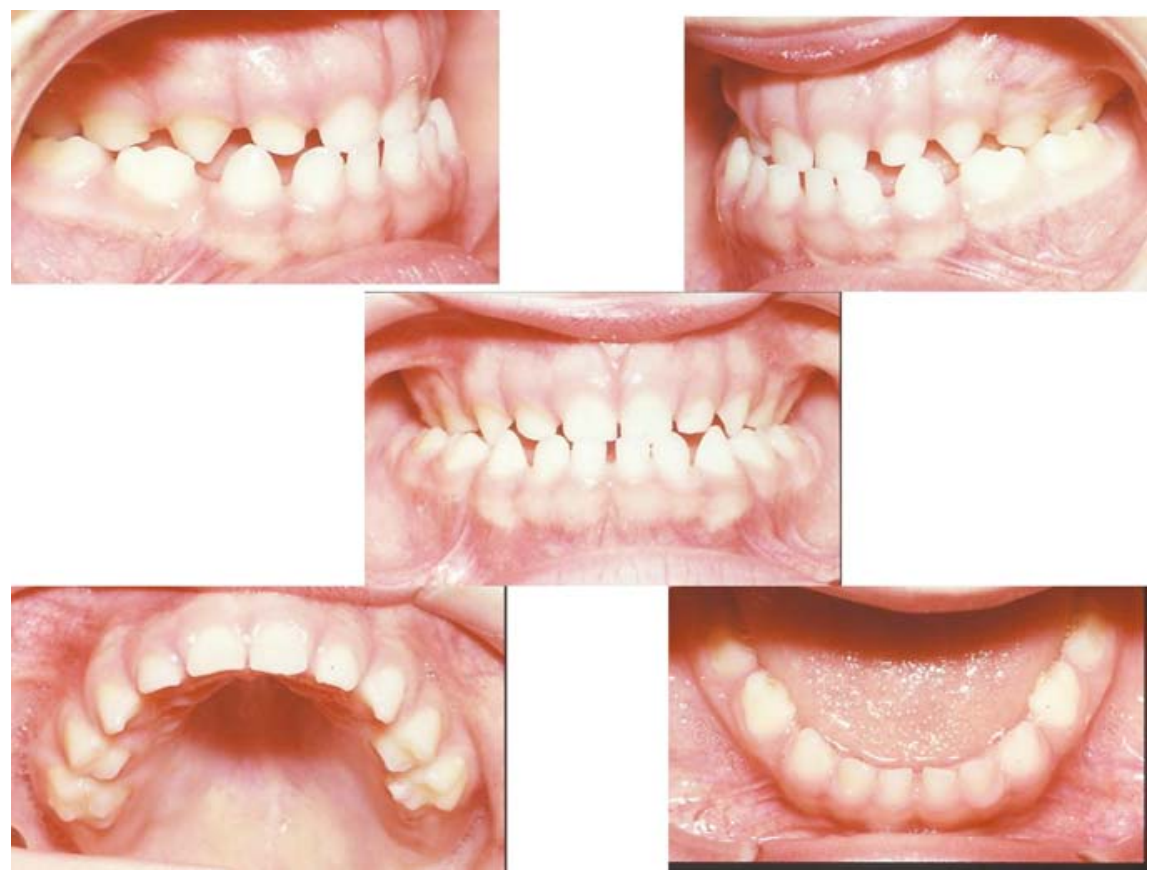

Figure 4. Pre-treatment clinical intraoral photographs.

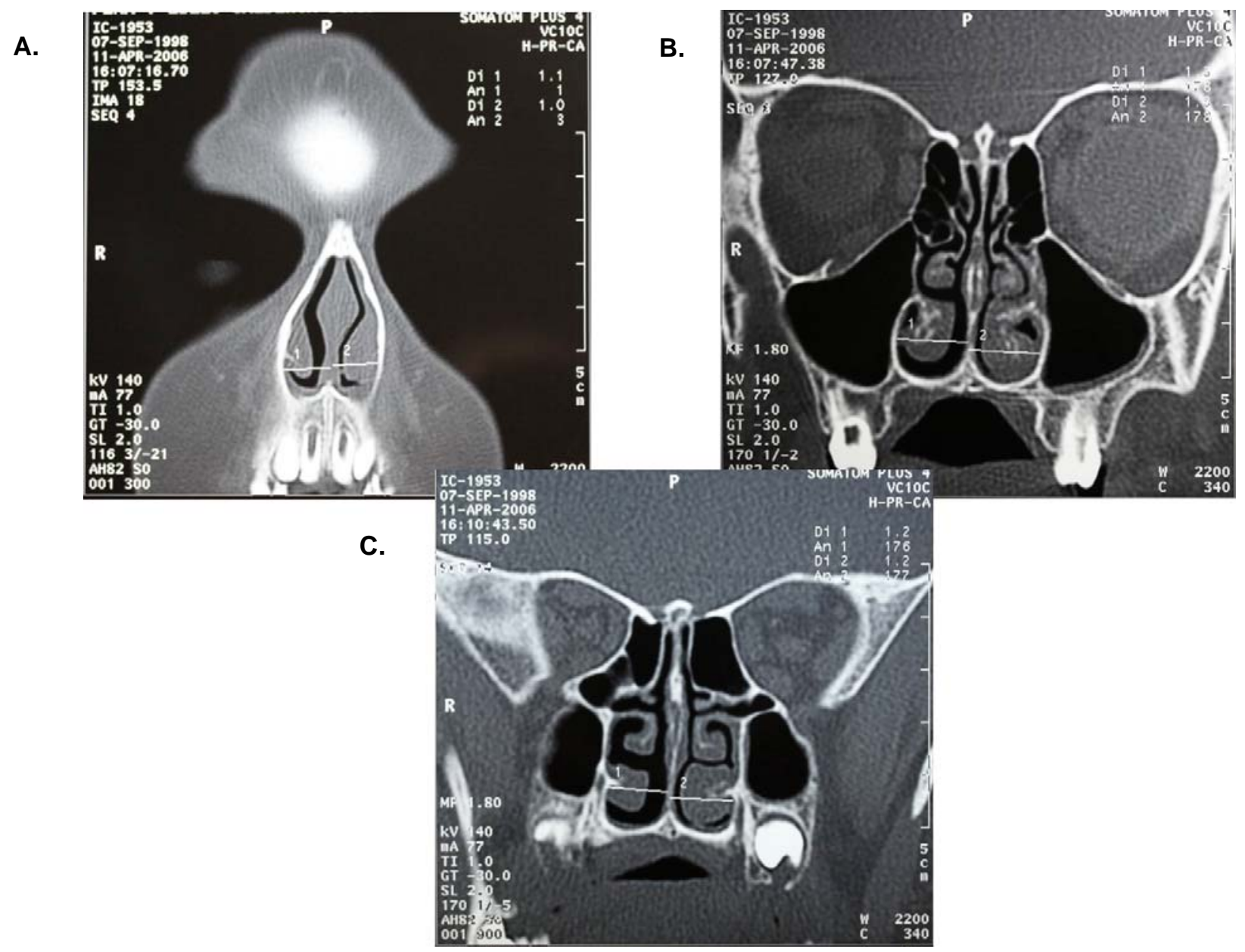

Figure 5. Pre-treatment CT scan measurements. A. Anterior coronal slice. B. Middle coronal slice. C. Posterior coronal slice. 


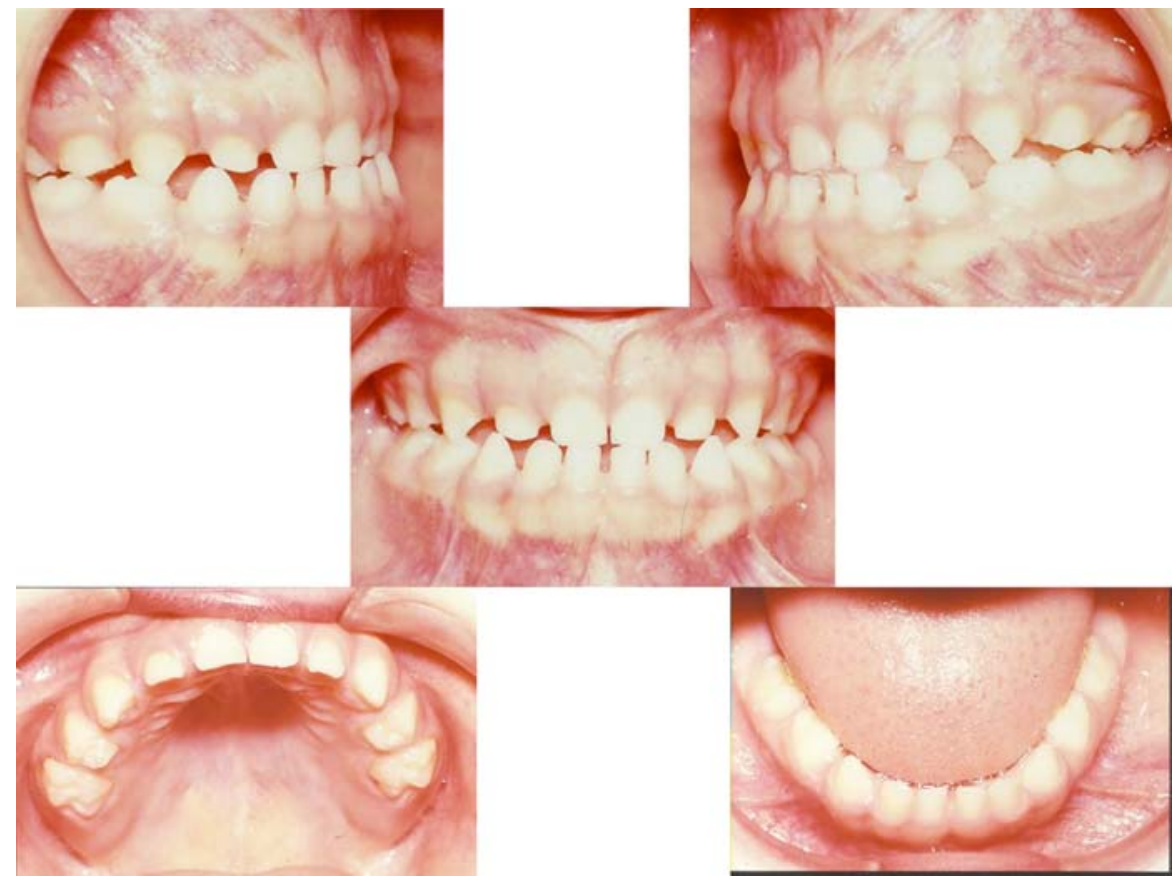

Figure 6. Post-treatment clinical intraoral photographs.

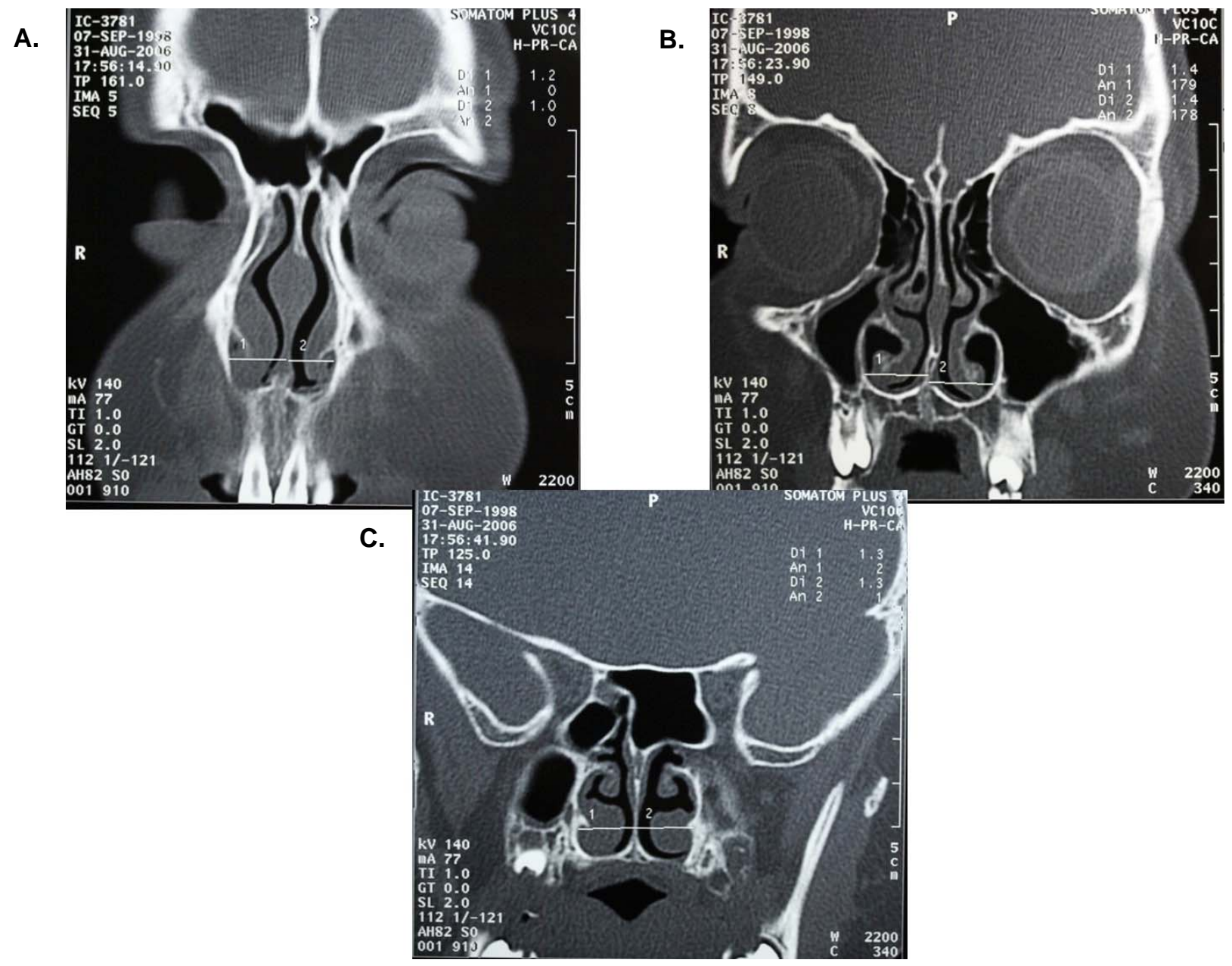

Figure 7. Post-treatment CT scan measurements. A. Anterior coronal slice. B. Middle coronal slice. C. Posterior coronal slice. 
A.

C.

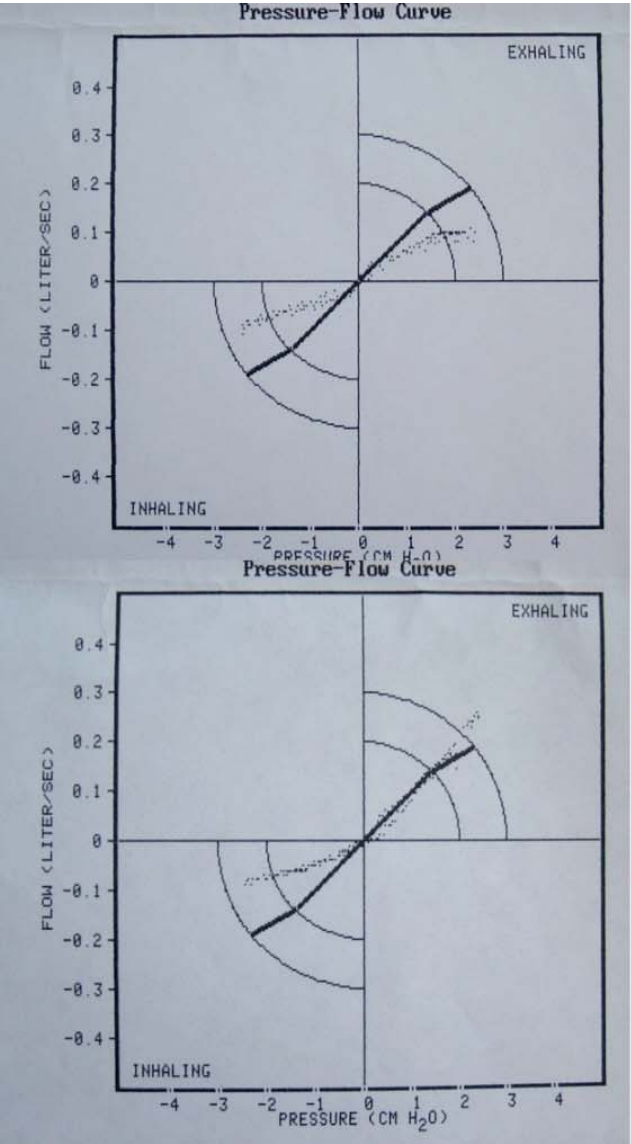

B.

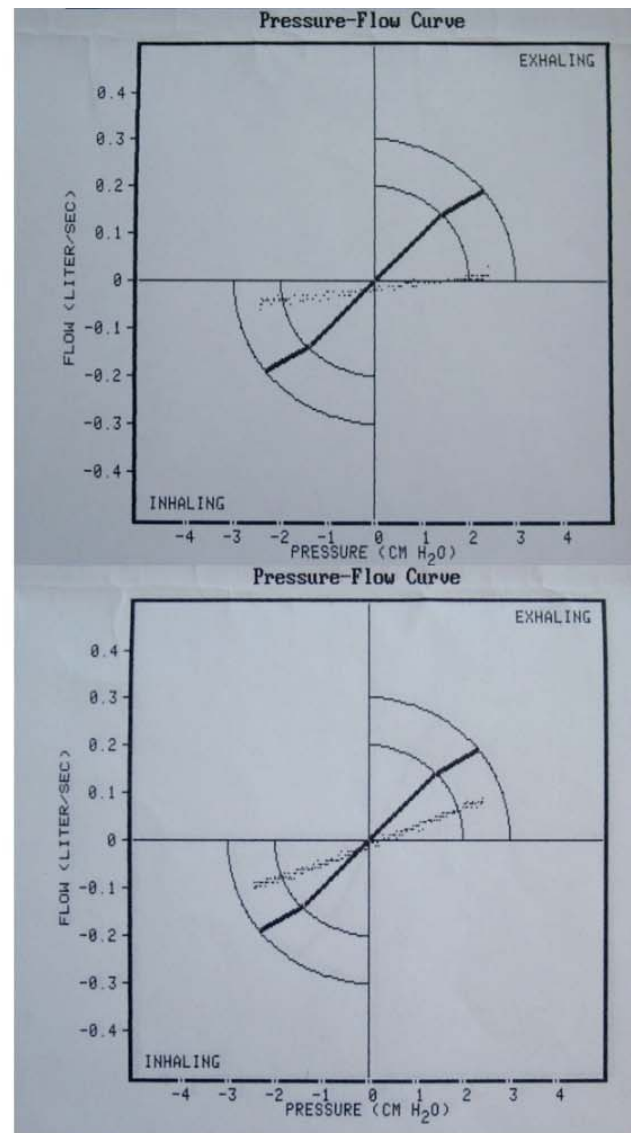

Figure 8. Rhinomanometry diagrams. Black line represents normal values. Dotted line shows patient's measurement. A. Pre-treatment left side. B. Pre-treatment right side. C. Post-treatment left side. D. Post-treatment right side.

be avoided since cephalometric measurements can also be drawn from computed tomography $[40,41]$.

\section{CONCLUSIONS}

All patients treated with RME improved their oral breathing habit clinically and there was also statistical evidence that the nasal cavity increased its transversal dimensions, and patients increased their airflow through the nasal cavity. Although this study was performed in a small number of patients, the results showed very clearly the importance of the orthodontist in the improvement of nasal breathing.

\section{REFERENCES}

[1] Subtelny JD. Oral respiration: facial maldevelopment and corrective dentofacial orthopedics. Angle Orthod 1980; 50: 147-64.

[2] Samolinski B, Szczesnowicz-Dabrowska P. Relationship between inflammation of upper and lower respiratory airways. Otoryngol Pol 2002; 56: 49-55.
[3] Orvidas LJ, Beatty CW, Weaver AL. Antrochoanal polyps in children. Am J Rhinol 2001; 15: 321-5.

[4] Harris J, Robert E, Källén B. Epidemiology of choanal atresia with special reference to the CHARGE association. Pediatrics 1997; 99: 3637.

[5] Sturgis EM, Potter BO. Sarcomas of the head and neck region. Curr Opin Oncol 2003; 15: 23952.

[6] Mitchell TE, Pickles JM. Traumatic laryngocele. J Laryngol Otol 1998; 112: 482-4.

[7] Fairchild RC. A pediatrician views the tonsil and adenoid problem. In Forum of the tonsil and adenoid problem in orthodontics. Am J Orthod 1968; 54: 491-4.

[8] Krakauer LH, Guilherme A. Relationship between mouth breathing and postural alterations of children: a descriptive analysis. Int J Orofacial Myology 2000; 26: 13-23.

[9] Ueda K, Motegi E, Yata R, Torikai T, Harasaki M, Yamaguchi H. Lip seal study of Japanese adults with malocclusion. Bull Tokyo Dent Coll 2002; 43: 89-93. 
[10] Cordasco G,Cicciù D, Lo Giudice G, Matarese G,Nucera R,Mazza M. Kinesiographic investigations in children with increased nasal airway resistance. Bull Group Int Rech Sci Stomatol Odontol 1999; 41: 67-72.

[11] Schlenker WL, Jennings BD, Jeiroudi MT, Caruso $\mathrm{JM}$. The effects of chronic absence of active nasal respiration on the growth of the skull: a pilot study. Am J Orthod Dentofacial Orthop 2000; 117: 706-13.

[12] Faria PT, de Oliveira Ruellas AC, Matsumoto MA, Anselmo-Lima WT, Pereira FC. Dentofacial morphology of mouth breathing children. Braz Dent J 2002; 13: 129-32.

[13] Löfstrand-Tideström B,Thilander B, AhlqvistRastad J, Jakobsson O, Hultcrantz E. Breathing obstruction in relation to craniofacial and dental arch morphology in 4-year-old children. Eur J Orthod 1999; 21: 323-32.

[14] Mattar SE, Anselmo-Lima WT, Valera FC, Matsumoto MA. Skeletal and occlusal characteristics in mouth breathing pre-school children. J ClinPediatr Dent 2004; 28: 315-8.

[15] Mahony D, Karsten A, Linder-Aronson S. Effects of adenomatoidectomy and changed mode of breathing on incisor and molar dentoalveolar heights and anterior face heights. Aust Orthod $\mathrm{J}$ 2004; 20: 93-8.

[16] Zicari AM, Albani F,Ntrekou P, et al. Oral breathing and dental malocclusions. Eur $\mathrm{J}$ Paediatr Dent 2009; 10: 59-64.

[17] Angell EH. Treatment of irregularity of the permanent or adult teeth. Dent Cosmos 1860; 1: 540-4.

[18] Compadretti GC, Tasca I, Bonetti GA. Nasal airway measurements in children treated by rapid maxillary expansion. Am J Rhinol 2006; 20: 38593.

[19] Haight JS, Cole P. The site and function of the nasal valve. Laryngoscope 1983; 93: 49-55.

[20] Jones AS, Wight RG, Stevens JC, Beckingham $E$. The nasal valve: a physiological and clinical study. J Laryngol Otol 1988; 102: 1089-94.

[21] Hartgerink DV, Vig PS, Abbott DW. The effect of rapid maxillary expansion on nasal airway resistance. Am J Orthod Dentofacial Orthop 1987; 92: 381-9.

[22] Kilic N, Oktay $\mathrm{H}$. Effects of rapid maxillary expansion on nasal breathing and some nasorespiratory and breathing problems in growing children: a literature review. Int $\mathrm{J}$ Pediatr Otorhinolaryngol 2008; 72: 1595-601.

[23] Hershey HG, Stewart BL, Warren DW. Changes in nasal airway resistance associated with rapid maxillary expansion. Am J Orthod 1976; 69: 27484.
[24] Basciftci FA,Mutlu N, Karaman Al, Malkoc S, Kucukkolbasi $H$. Does the timming and method of rapid maxillary expansion have an effect on the changes in nasal dimensions? Angle Orthod 2002; 72: 118-23.

[25] Palaisa J, Ngan P, Martin C, Razmus T. Use of conventional tomography to evaluate changes in the nasal cavity with rapid palatal expansion. Am J Orthod Dentofacial Orthop 2007; 132: 458-66.

[26] Garrett BJ, Caruso JM. Rungcharassaeng K, Farrage JR, Kim JS, Taylor GD. Skeletal effects to the maxilla after rapid maxillary expansion assessed with cone-beam computed tomography. Am J Orthod Dentofacial Orthop 2008; 134: 8.e111.

[27] Cole P, Fenton RS. Contemporary rhinomanometry. JOtorhinolaryngol 2006; 35: 83-7.

[28] Zapletal A, Chalupová J. Nasal airflow and resistance measured by active anterior rhinomanometry in healthy children and adolescents. Pediatr Pulmonol 2002; 33: 174-8.

[29] Cole P, Ayiomanimitis A, Ohki M. Anterior and posterior rhinomanometry. Rhinology 1989; 27: 257-62.

[30] Suzina AH, Hamzah M,Samsudin AR. Active anterior rhinomanometryanalysis in normal adult Malays. J Laryngol Otol 2003; 117: 605-8.

[31] Suzina AH, Hamzah M, Samsudin AR. Objective assessment of nasal resistance in patients with nasal disease. J Laryngol Otol 2003; 117: 60913.

[32] Clement PA, Kaufman L, Rousseeuw P. Active anterior rhinomanometry in pre- and postoperative evaluation, use of Brom's mathematical model. Rhinology 1983; 21: 121-33.

[33] Ehrler $\mathrm{T}$. The effect of rapid maxillary expansion on nasal cavity volume and nasal airway resistance (abstract). Am J Orthod Dentofacial Orthop 2005; 128: 549 .

[34] Asanza S, Cisneros GJ, Nieberg LG. Comparison of hyrax and bonded expansion appliances. Angle Orthod 1997; 67: 15-22.

[35] Chiari S, Romsdorfer P, Swoboda H, Bantleon HP, Freudenthaler J. Effects of rapid maxillary expansion on the airways and ears - a pilot study. Eur J Orthod 2009; 31: 135-41.

[36] Monini S, Malagola C, Villa MP, et al. Rapid maxillary expansion for the treatment of nasal obstruction in children younger than 12 years. Arch Otolaryngol Head Neck Surg 2009; 135: 22-7.

[37] Halicioglu K, Kilic N, Yavuz I, Aktan B. Effects of rapid maxillary expansion with a memory palatal split screw on the morphology of the maxillary dental arch and nasal airway resistance. Eur $\mathrm{J}$ Orthod 2010; 32: 716-20. 
[38] Scarfe WC, Farman AG, Sukovic P. Clinical applications of cone-beam computed tomography in dental practice. J Can Dent Assoc 2006; 72: 7580.

[39] Berco M,Rigali PH Jr, Miner RM, DeLuca S, Anderson NK, Will LA. Accuracy and reliability of linear cephalometric measurements from conebeam computed tomography scans of a dry human skull. Am J Orthod Dentofacial Orthop 2009; 136: 17.e1-9.
[40] Cattaneo PM, Bloch CB, Calmar D, Hjortshoj M, Melsen B. Comparison between conventional and cone-beam computed tomographygenerated cephalograms. Am J Orthod Dentofacial Orthop 2008; 134: 798-802.

[41] Kumar V, Ludlow J, Soares Cevidane LH, Mol A. In vivo comparison of conventional and cone beam CT synthesized cephalograms. Angle Orthod 2008; 78: 873-9. 